\title{
English for the Workplace: Doing Patient- Centred Care in Medical Communication
}

\author{
Maria R. Dahm and Lynda Yates
}

Canada, like other first-world countries, relies in large part on professional immigrants trained in other cultures and languages to complement its workforce in a wide range of professions, including medicine. International medical graduates (IMGs) who are nonnative English-speaking (NNES) and who have trained in different medical contexts are often unfamiliar with the sociopragmatic norms underlying both general communication and medical practice in their new host countries, and as a result they can have difficulty using the pragmalinguistic resources needed to strike the appropriate interpersonal note in patient-centred approaches to communication. In this article we used data collected through roleplays performed in an Australian setting by practicing, locally trained, native English-speaking (NES) doctors and NNES IMGs to identify the features of patient-centred medical communication that the latter can find challenging. This approach allowed us to use the discourse to highlight those features of approachability that are likely to be relevant to immigrant professionals in both Canada and Australia. It also helped us to illustrate how discourse data can be used to identify culturally appropriate ways of communicating that can, in turn, contribute to an accurate evidence base from which culturally appropriate communication courses for IMGs and other professionals may be developed.

Le Canada, tel d'autres pays développés, s'appuie largement sur les immigrants professionnels formés dans d'autres cultures et langues pour compléter sa maind'œuvre dans un large éventail de professions, y compris la médecine. Les diplômés d'écoles de médecine étrangères dont la langue maternelle n'est pas l'anglais et qui ont été formés dans des milieux médicaux différents ne connaissent pas souvent les normes socio-pragmatiques qui sous-tendent tant la communication générale que la pratique médicale dans leur nouveau pays hôte. Par conséquent, ils peuvent éprouver des difficultés à employer les ressources pragma-linguistique nécessaires pour établir un ton approprié sur le plan interpersonnel qui caractérise les approches centrées sur le patient. Cette recherche s'appuie sur des données recueillies lors de jeux de rôles dans un milieu australien impliquant des médecins praticiens formés sur place, de langue maternelle anglaise et des diplômés d'écoles de médecine étrangères dont la langue maternelle n'est pas l'anglais. L'objectif des jeux de rôles était d'identifier les caractéristiques de la communication employée en milieu médical centrée sur le patient qui pourraient présenter des défis aux diplômés formés à l'étranger. Cette approche nous a permis d'utiliser le discours pour faire ressortir les caractéristiques d'un médecin d'un abord facile, caractéristiques susceptibles d'être pertinentes aux immigrants diplômés au Canada et en 
Australie. De plus, elle nous a permis d'illustrer la mesure dans laquelle les données de discours peuvent servir dans l'identification de modes de communication adaptés à la culture. Ces données peuvent, par la suite, contribuer à la création d'une base de données précise portant sur la communication adaptée à la culture et à partir de laquelle peuvent être développés des cours de communication pour les diplômés d'écoles de médecine étrangères et d'autres professionnels.

Many first-world countries such as Canada and Australia depend on international medical graduates (IMGs) to support the medical workforce in areas of need (Birrell \& Schwartz, 2006; Mullan, 2005). In Australia, as in Canada, roughly a quarter of the medical workforce was trained in another country (25.4\% and 25.2\% respectively; Australian Institute of Health and Welfare [AIHW], 2011; Canadian Medical Association [CMA], 2013). A very heterogeneous group, these IMGs include native and nonnative English speakers, and doctors trained in medical environments similar to those found in Canada and Australia, as well as those trained in countries where the medical facilities and customs are very different. Although about 37\% of the IMGs in Canada were trained in English-speaking countries (United Kingdom, Ireland, Australia, New Zealand, United States, and South Africa; CMA, 2013), the majority $(63 \%)$ are from countries such as India, Egypt, and Pakistan. Comparable detailed figures relating to the origins of IMGs already practicing in the country are not available for Australia, but country of origin data from the Australian Medical Council (AMC) show that from 2008 to 2012 about half (46.4\%) of all IMGs qualifying for practice came from countries outside the first circle (Kachru, 1992), including countries such as India, Pakistan and Sri Lanka, where a different variety of English is spoken (AMC, 2009, 2011, 2012a, 2012b).

In addition to the challenges of working in an unfamiliar medical system, these doctors can also face considerable difficulties in daily communications with patients, families, and colleagues (Hall, Keely, Dojeiji, Byszewski, \& Marks, 2004; McDonnell \& Usherwood, 2008; Tipton, 2005). In addition to the more obvious language difficulties with vocabulary, grammar, pronunciation, and an understanding of accents and colloquialisms, they can also struggle with the less salient but vitally important interpersonal features of language use, such as how to build rapport and show empathy (Hall et al., 2004; McDonnell \& Usherwood, 2008; Pilotto, Duncan, \& Anderson-Wurf, 2007). Moreover, many may not be familiar with the demands of the patientcentred models of care expected in developed medical environments in Canada and Australia, but less common in developing countries where medical facilities are very stretched (Dahm, 2011b; Khalil \& Bhopal, 2009).

In this article we focus on the communication challenges facing doctors who trained in medical environments very different from those found in Canada and Australia using a language other than English, in order to inform 
communications training designed specifically for doctors from language backgrounds other than English, and to illustrate how a close analysis of professional discourse can be transferred to ESL classes preparing for work environments beyond the medical world. We draw on clinical role-plays performed by practicing locally trained native English-speaking (NES) doctors and nonnative English-speaking (NNES) IMGs to identify the communication features of the kind of patient-centred approach to medical communication that will be expected of them. Although specific features and approaches to communication in Canada and Australia likely differ in some minor respects, our aims are to highlight features that are relevant in both cultures and to illustrate how discourse data can be used to identify culturally appropriate ways of communicating in a medical setting in order to provide an accurate evidence base from which culturally appropriate medical communication courses for IMGs may be developed.

\section{Background}

The subtle culture-specific communication skills that are the focus of this article can be understood using the distinction between sociopragmatic and pragmalinguistic dimensions of language use proposed by Thomas (1983). Sociopragmatic skills relate to the cultural values and expectations underlying and driving interactions in particular cultural contexts, including workplace contexts (see Holmes \& Riddiford, 2011). Pragmalinguistic skills concern a speaker's ability to understand and appropriately deploy the linguistic means available in a language in order to achieve their aims. For example, while the sociopragmatic expectations in both Germany and Australia are that new employees or important visitors should be introduced, on a pragmalinguistic level German speakers might prefer formal introductions using multiple honorifics and surnames such as Herr/Frau/Doktor Schmidt, whereas Australians might introduce themselves more informally, giving their first name John/Jane and so forth (Clyne, 2006).

Such aspects of communication can be particularly difficult for IMGs to understand and acquire as, in both Australia and Canada, communication and other kinds of support programs are often limited (McGrath, Henderson, Holewa, Henderson, \& Tamargo, 2012), poorly integrated (Zulla, Baerlocher, \& Verma, 2008), focused on systemic rather than communication issues (e.g., Lockyer, Fidler, de Gara, \& Keefe, 2010), or inaccessible due to geographic isolation or financial constraints (Sommer, MacDonald, Bulsara, \& Lim, 2012). Moreover, such micropragmatic features are frequently underrepresented in or entirely left out of the curriculum of both general and specialist communication programs, in part because a reliable context-relevant evidence base is still lacking (Derwing \& Waugh, 2012; Yates, 2008).

In medical and other settings, however, the failure to understand local sociopragmatic values or follow pragmalinguistic norms of interpersonal 
communication can be far-reaching: for instance, IMGs could fail to discuss what they believe to be taboo topics such as mental health (sociopragmatic failure), or they could be perceived as being unfriendly or too direct and therefore rude (pragmalinguistic failure; see Clyne, 2006; Yates, 2010). The pragmalinguistic features of specialized medical discourse should be viewed as embedded within the broader cultural context as well as in the unique (sociopragmatic) settings that exist for communication in everyday and workplace contexts within a particular culture. Thus, generally held cultural perspectives will be reflected in the communicative values in a culture, that is, the values to which interactants orient when they speak. These, in turn, will influence the exact nature of industry- or context-specific communicative values, and thus the specific pragmalinguistic devices that will be used and expected in those contexts. So the particular communicative (pragmalinguistic) features that doctors will use in a consultation in Canada or Australia will be influenced by the approach taken to medicine (patient-centred care) that will have percolated through the cultural values that are current in the community more generally.

In the following section, we identify some of the interpersonal features of communication that appear to be important to the practice of patient-centred care in consultations in English-speaking medical environments such as Australia and Canada. We suggest that these "approachability" features are ways in which doctors can reduce interpersonal distance and signal that they are open, empathic listeners, and that, once identified, these features can be explicitly taught to IMGs as part of their orientation programs.

\section{Communicative and Medical Culture}

As a country of only recent English-speaking settlement, the communicative culture in Australia has been argued to favour informality and "mateship" such that informal language may be used even in situations where, in other varieties of English and in other languages, more formal language might be expected (Horne, 1964). This informality should not be regarded as indicating intimacy, however, but as contributing to a communicative ethos that has been described as a fiction of egalitarianism (Wierzbicka, 1994; Yates, 2000). A similar ethos has also been identified as playing an important role in rapportbuilding in workplace contexts outside Australia (Marra, Vine, \& Holmes, 2008; Newton, 2004).

Moreover, a "tall poppy syndrome" that discourages the overt expression of superiority or "big-noting" and thus further discourages displays of social distance also seems to play an important role in communicative expectations in Australian culture (Gassner, 2012; Goddard, 2006, 2009; Peeters, 2004). Although the degree to which informality is expected and social distance downplayed may differ across English-speaking communities, Canada, as a country with a similarly recent history of English-speaking immigration, shares with Australia a less hierarchical and more informal communicative 
ethos (Laroche \& Rutherford, 2007) than many immigrant IMGs are used to, and they can therefore find such sociopragmatic values difficult to both recognize and orient to in practice (McDonnell \& Usherwood, 2008; Pilotto et al., 2007).

As noted above, a patient-centred approach to medical communication is favoured in many Western contexts, including Australia and Canada, as this allows the medical practitioner insight into patient perspectives on their illness, treatment, and management preferences; this patient participation and joint decision-making have been associated with better health outcomes, increased patient compliance, and higher patient and physician satisfaction (Cordella \& Musgrave, 2009; Levinson, Gorawara-Bhat, \& Lamb, 2000; Stewart et al., 2003; Street, 1991). A quintessential patient-centred approach incorporates six components, which can be realized through various communication strategies. Core components of a patient-centred approach to health care are (Stewart et al., 2003)

- exploring both the disease and the illness experience

- understanding the whole person

- finding common ground

- incorporating prevention and health promotion

- enhancing the patient-doctor relationship, and

- being realistic.

These can increase the communicative demands on IMGs who are already coping with life in a new country and medical system, and working in a language and culture in which they have not yet achieved full pragmatic proficiency. For example, they need to be able to formulate open questions that trigger patient narratives giving insight into how they perceive their illness and how it affects their person, and their social and work environments. The doctor needs to be able to elicit a patient's concerns and beliefs so that they can establish a common foundation for shared decision-making. Taking a little time for small talk about shared experiences and listening actively and attending to patient cues give doctors the chance to express empathy, strengthen the doctor-patient relationship, and show that they care about, and want to understand, the patient as a whole.

However, NNES IMGs who were educated in medical environments that favour more biomedical or paternalistic approaches to healthcare, and who were raised in a communicative ethos where hierarchy, position, and social indexing are more overt, may not only have little experience with patientcentred care, but may also be unfamiliar with exactly how it is practiced in Canada or Australia (Dahm, 2011b). It by no means follows that, once acquainted with the basic principles and sociopragmatics of a patient-centred consultation, IMGs will automatically recognize the communicative means of putting the pragmalinguistics into practice - that is, exactly how to show empathy and reassurance in a way that is perceived as genuine rather than 
formulaic, or how to reduce power distance and be perceived as friendly and approachable in a way that is consonant with their role as doctor in their new environment. They may therefore struggle to select suitable communicative strategies through which they can present themselves as approachable, and through which they can signal their readiness to establish strong, trusting, and more apparently egalitarian relationships. Yet their long-term success as medical practitioners in their new countries can rest on their ability to deploy these means as they approach the person as well as the disease in a culturally appropriate manner. We consider some of these pragmalinguistic means below.

\section{Approachability Features}

A review of the literature on medical communication, the discursive reduction of social distance, and the establishment of rapport and trust suggests that the following subtle communication features can be important in perceptions of approachability:

- interpersonal strategies:

- greeting/introduction, familiar naming/forms of address (Moore, Yelland, \& Ng, 2011)

- small talk (Hudak \& Maynard, 2011; Ragan, 2000)

- interpersonal side sequences and personal disclosure (O'Grady, Dahm, Roger, \& Yates, in press)

- genuine empathy/reassurance statements (Derksen, Bensing, \& LagroJanssen, 2013; Epstein, 2000; Norfolk, Birdi, \& Walsh, 2007; O'Grady, 2011)

- informal language (Yates, 2005)

- tailored explanations (Hadlow \& Pitts, 1991; Street, 2003; Tannen \& Wallat, 1987)

- softening strategies (vague language, hedges, bushes; Caffi, 1999; Gassner, 2012)

Interpersonal strategies such as greetings and introductions, small talk, interpersonal asides, and personal disclosure from the doctor can help to reduce power asymmetries, soften face threats, and create a relaxed, informal, conversational atmosphere (Hudak \& Maynard, 2011; Moore et al., 2011; Ragan, 2000; Yates, 2005). Thus the use of reciprocal terms of address, particularly first names, can help to decrease power imbalances, but may not be routine in all cultures. Similarly, initiating or picking up on opportunities for small talk or encouraging interpersonal side sequences or personal disclosures can help to build rapport and trust (Hudak \& Maynard, 2011; O'Grady et al., in press; Ragan, 2000). Following up on patient cues with relational talk also provides doctors with opportunities to explore their social world, acknowledge their hopes or worries, and tailor their displays of empathy or reassurance to the individual patient. 
Such displays can seem to be more "genuine" (Epstein, 2000) and stand in stark contrast to formulaic tokenistic responses that are rote learned and rehearsed and can sound insincere (Dahm, 2011a; see also Martin, 2003). Done appropriately, empathic and reassuring behaviour can help to decrease anxiety, relieve distress, increase therapeutic rapport, and improve patient satisfaction and health outcomes (Derksen et al., 2013; Norfolk et al., 2007; O'Grady, 2011).

As noted above, informal language can help to reduce social distance (Hall, Roter, \& Katz, 1988; Street, 1991; Yates, 2005), and the use of lay terms together with relational talk can help doctors to tailor their explanation to the level of understanding of their patients, thereby minimizing misunderstandings and improving patient compliance (Hadlow \& Pitts, 1991; Street, 2003; Tannen \& Wallat, 1987).

The use of softening strategies can also help to weaken power/knowledge imbalances, thus allowing patients the space to become active, more equal partners in negotiations in a more relaxed consultation atmosphere (Adolphs, Atkins, \& Harvey, 2007; Caffi, 1999; Gassner, 2012; Prince, Frader, \& Bosk, 1982). They can also soften the impact of potentially distressing topics, mitigate threats to face, and provide reassurance, all of which can help doctors to signal their approachability, establish rapport, and build stronger relationship with patients (Caffi, 1999).

Caffi (1999) identifies three fundamental types of mitigation strategies: bushes, hedges, and shields. Bushes and hedges are lexicalized and relate to the content of a message, whereas shields are embedded within deeper language structures. Bushes can be used in medical consultation to downplay the seriousness of the issue under discussion, such as in "his feet were just a little bit blue" (see Adolphs et al., 2007; example adapted from Prince et al., 1982, p. 85), while hedges downgrade the force of an utterance so that, for example, a diagnosis might sound more like a hypothesis, as in "It's probably a consequence of a circulation problem" (Caffi, 1999, p. 893). Hedges can also be approximators that reduce the seriousness of medical realities that are close to but not identical to prototypical clinical presentations (as in "His feet were sort of blue"; Prince et al., 1982, p. 85) or as exemplars to enable patients to provide more complex information during history ("Any intense headache or confusion or anything?"; Adolphs et al., 2007, p. 67). Shields express speakers' reservation regarding their commitment to the truth value of a statement, as in quotational or attribution shields ("The mother said/I think his feet were blue") and various forms of objectivization. Through the deletion of agents such as "I" or "you," a shift to passive forms (as in "Medicine needs to be given"), or a shift to plural pronouns (as in "We need to give medicine"), these objectivization shields complicate the straight line from doctor to action, suggesting shared or at least "natural" action (Caffi, 1999). It should be noted, however, that switches to "we" can be inclusive (that is, we = doctor and patient) or exclusive (that is, we $=$ doctors as a professional group). 
These subtle interpersonal elements of communication seem to be difficult, not only for IMGs, but also for other NNES professionals in Canada and Australia to acquire and use (see, for example, Derwing \& Waugh, 2012; Pilotto et al., 2007; Yates, 2008), because of transfer issues from their first language and cultures, and also because they are so seldom addressed in teaching materials (but see recent additions to the Centre for Canadian Language Benchmarks [CCLB] website; CCLB, 2009, 2012). Unfortunately, however, failure to master such interpersonal language skills can make speakers appear uncaring and authoritarian (Bates \& Andrew, 2001). Successfully identifying and adopting the communication features relevant for their specific cultural environment should enable overseas-trained professionals to build stronger relationships, conduct patient-centred interviews, and be perceived as more approachable by patients.

The aims of the present article are to show how discourse data can be utilized to identify the particular culturally appropriate communication features that allow IMGs to do patient-centred care within a specific cultural environment-in our case, Australia - and to suggest some ways in which findings from such studies can inform communication training for IMGs.

\section{Methodology}

Role-plays using actual professionals, rather than students or others pretending to be professionals, were chosen as the most reliable means of providing insight into the actual language behaviour of doctors as they communicate with colleagues and the public. Although naturally occurring data offer the advantage of authenticity, as methodological debates in the literature have highlighted, they are also not only more difficult to collect from an ethical standpoint, but they are also, almost by definition, more difficult to control for different variables. Role-plays, on the other hand, can guarantee the exploration of the regularities of a particular situation in a way that is difficult to achieve with naturally occurring data (see discussions in Bataller \& Shively, 2011; Kasper, 2000).

For the present study, the likelihood that the language samples collected were as close to naturally occurring data as possible was increased by recruiting participants representative of NNES IMGS and NES locally trained professionals. We ensured that the nonnative group was made up of IMGs $(n=3$, henceforth NNES) who hoped to practice in Australia but who lacked local experience, while the native speaker ${ }^{1}$ group consisted of medical professionals ( $n=4$, henceforth NES) who had trained in Australia and now actively practiced in a large Sydney hospital and hence were familiar with situations of the kind developed for the pilot study role-plays. Participants were recruited through the New South Wales Royal Australian College of General Practitioners (a large public hospital in Western Sydney) and the medical school of a Sydney university, using opportunistic sampling. Their levels of medical experience varied from novice to seasoned specialist (see Table 1). 


\section{Table 1}

Participant Demographics

\begin{tabular}{|c|c|c|c|c|c|}
\hline $\begin{array}{l}\text { Pseudo- } \\
\text { nym } \\
\text { (gender) }\end{array}$ & $\begin{array}{l}\text { Region } \\
\text { of origin }\end{array}$ & $\begin{array}{l}\text { Medical } \\
\text { specialty }\end{array}$ & $\begin{array}{l}\text { Years of } \\
\text { practical } \\
\text { experience }\end{array}$ & $\begin{array}{l}\text { Local social } \\
\text { contact }\end{array}$ & $\begin{array}{l}\text { Local practical } \\
\text { experience }\end{array}$ \\
\hline \multicolumn{6}{|c|}{ NNES IMGs } \\
\hline $\begin{array}{l}\text { Ali } \\
\text { (male) }\end{array}$ & $\begin{array}{l}\text { Southern } \\
\text { Asia }\end{array}$ & $\begin{array}{l}\text { Respiratory } \\
\text { medicine }\end{array}$ & $10+$ & $\begin{array}{l}\text { - Language other } \\
\text { than English } \\
\text { (LOTE) at home } \\
\text { - NNES spouse } \\
\text { - English very often } \\
\text { with children \& at } \\
\text { work }\end{array}$ & $\begin{array}{l}\text { - } 5 \text { years in Australia } \\
\text { - Local experience in } \\
\text { auxiliary role (none } \\
\text { in his speciality) }\end{array}$ \\
\hline $\begin{array}{l}\text { Bron } \\
\text { (male) }\end{array}$ & $\begin{array}{l}\text { South- } \\
\text { eastern } \\
\text { Europe }\end{array}$ & $\mathrm{PhD}$ & None & $\begin{array}{l}\text { - English every day } \\
\text { at home \& with } \\
\text { social contacts } \\
\text { - NES spouse }\end{array}$ & $\begin{array}{l}\text { - } 3 \text { years in Australia } \\
\text { - Medical degree } \\
\text { without experience } \\
\text { (PhD student) }\end{array}$ \\
\hline $\begin{array}{l}\text { Fara } \\
\text { (female) }\end{array}$ & $\begin{array}{l}\text { Central } \\
\text { Asia }\end{array}$ & $\begin{array}{l}\text { Internal } \\
\text { medicine }\end{array}$ & $10+$ & $\begin{array}{l}\text { - LOTE at home } \\
\text { - NNES spouse } \\
\text { - English with chil- } \\
\text { dren }\end{array}$ & $\begin{array}{l}\text { - } 8 \text { Years in Australia } \\
\text { - No local experience }\end{array}$ \\
\hline \multicolumn{6}{|c|}{ NES Australian-trained } \\
\hline $\begin{array}{l}\text { Anne } \\
\text { (female) }\end{array}$ & Australia & $\begin{array}{l}\text { Intensive } \\
\text { care }\end{array}$ & $10+$ & $\begin{array}{l}\text { - NNES parents } \\
\text { - NES spouse }\end{array}$ & $\begin{array}{l}\text { - } 10+\text { years experi- } \\
\text { ence } \\
\text { - Intensive care spe- } \\
\text { cialist }\end{array}$ \\
\hline $\begin{array}{l}\text { Lynne } \\
\text { (female) }\end{array}$ & Australia & $\begin{array}{l}\text { Nurse, } \\
\text { medical } \\
\text { educator }\end{array}$ & $10+$ & $\begin{array}{l}\text { - English monolin- } \\
\text { gual }\end{array}$ & $\begin{array}{l}\text { - } 10+\text { years experi- } \\
\text { ence } \\
\text { - Nurse \& medical } \\
\text { educator }\end{array}$ \\
\hline $\begin{array}{l}\text { Nina } \\
\text { (female) }\end{array}$ & Australia & $\begin{array}{l}\text { Internship in } \\
\text { emergency }\end{array}$ & $2+$ & $\begin{array}{l}\text { - NNES parents } \\
\text { - English everyday }\end{array}$ & $\begin{array}{l}\text { - } 2 \text { years experience } \\
\text { - Intern on rotation }\end{array}$ \\
\hline $\begin{array}{l}\text { Rebecca } \\
\text { (female) }\end{array}$ & Australia & $\begin{array}{l}\text { General } \\
\text { medicine }\end{array}$ & $5+$ & $\begin{array}{l}\text { - English family } \\
\text { background }\end{array}$ & $\begin{array}{l}\text { - } 5+\text { years experi- } \\
\text { ence } \\
\text { - Intensive care sen- } \\
\text { ior registrar }\end{array}$ \\
\hline
\end{tabular}

\section{Role-Play Scenarios}

In collaboration with a specialist medical communications organization, the Pam McLean Centre for Cancer Communication, we developed two consecutive role-plays set in a hospital emergency department around the following scenario: 
Five-year-old Aaron is staying with his grandfather, Jim, while his parents are on vacation. Aaron was involved in a bike accident, and Jim accompanied him to the emergency department. Jim has been informed that $x$-rays showed a fractured leg. Aaron has been taken for further tests and suffered an adverse reaction to a contrast solution required for an $x$-ray computed tomography (CT). Jim is unaware of this latest development and anxious for news.

The role-plays were designed to reflect situations that hospital doctors face on a daily basis, and participants confirmed to us in their exit interviews that they did, indeed, reflect scenarios they had commonly encountered in that environment. The two role-plays followed on from each other sequentially. In both role-plays, participants took on the role of a doctor who had just come on duty. In Role-play 1, participants performed a routine patient handover about Aaron's case with a nurse (Sandra). Sandra then led the participants into a different room for Role-play 2, where they were required to update Jim on the condition of his grandson. Sandra (the nurse) and Jim (the grandfather) were played by experienced and rehearsed actors. Only one actor was present in each role-play: Sandra (female) in Role-play 1, Jim (male) in Role-play 2. Role-play 1 therefore allows insight into interprofessional communication strategies, and Role-play 2 into doctor-patient communication strategies. Because the analysis in this article focuses on doctor-patient communication, we draw on findings relating to Role-play 2. The implications for interprofessional communications training of the findings from Role-play 1 are discussed in Yates, Dahm, Roger, and Cartmill (2013).

\section{Data Collection and Analysis}

Following completion of appropriate ethics procedures, the role-plays were conducted in specialized simulation training facilities that allowed for inconspicuous and unobtrusive video recording through permanently installed ceiling cameras. All participants were volunteers. Brief exit interviews were conducted to collect social and professional background data (see Table 1) and the participants' reactions to the role-plays, including whether they found them to reflect typical scenarios with which they were familiar. They were not audio-recorded, but notes were taken.

A total of 14 role-plays (7 each for Role-plays 1 and 2) were collected, transcribed, and de-identified, and participants were assigned pseudonyms to reflect gender and association with NNES or NES participant groups (see Table 1). All transcripts were analyzed by the authors for successful and less successful features of medical communication using a reiterative data-driven approach, adopting a range of techniques and frameworks from discourse analysis, interlanguage pragmatics, and medical communication (Harvey \& Adolphs, 2012; Holmes, 2000; Spencer-Oatey, Işik-Güler, \& Stadler, 2012). First assessments were conducted independently by the authors, and dis- 
cussion of the initial findings led to the extraction from the data, with the help of relevant literature, of a set of subtle communication features for the delivery of patient-centred care. The authors again reviewed the transcripts independently and then jointly discussed findings, focusing on these subtle discourse features.

\section{Findings and Discussion}

The seven interactions collected for Role-play 2 ran for an average of 9 minutes (range: 7-10.5 minutes) and averaged 1,880 words (range: 1,666-,2050 words). NESs spent on average about 1.5 minutes less and 1,000 words fewer than NNESs to complete Role-play 2 (8.5 minutes and 1,838 words, as compared to 10 minutes and 1,940 words). Given the small number of participants and absence of male participants in the native speaker group, no reliable conclusion can be drawn regarding the influence of native language background or gender on the length of Role-play 2, although it may be that NESs were more efficient in concluding Role-play 2 as they were more familiar with undertaking similar tasks in English.

The findings revealed that, in comparison with the NESs trained in Australia, the NNES IMGs were less successful in making their communication style patient-centred and appeared to be more limited in their use of the approachability features discussed above. Table 2 provides an overview of the approachability features that were used by all participants. We marked (+) when a participant used a feature largely successfully or displayed a wide range of linguistic expression for a certain feature; (0) indicates marginally successful/low range of use; and use that was unsuccessful/very limited in range or totally absent is marked (-).

As shown in Table 2 and discussed in more detail below, the NNESs were more formal in their terms of address, used more formal language and medical terminology, and provided explanations that were less successfully tailored to the needs of their interlocutor. They were also more restricted in the range of reassurance and empathy statements they used, and drew from a more limited range of softening strategies than the Australian doctors.

\section{Interpersonal Strategies}

As addressed above, there were noticeable differences in the way participants used greetings, forms of address, and small talk. However, other strategies identified as important in the literature, such as interpersonal side-sequences or personal disclosure, were not observed at all, perhaps because of time constraints or because they are more characteristic of other kinds of consultations or settings (see, for example, O'Grady et al., in press). 
Table 2

Participants' Use of Approachability Features

\begin{tabular}{|c|c|c|c|c|c|c|c|}
\hline \multirow[b]{2}{*}{$\begin{array}{l}\text { Approachability } \\
\text { feature }\end{array}$} & \multicolumn{3}{|c|}{ NNESs (IMG) } & \multicolumn{4}{|c|}{ NESs (Australian-trained) } \\
\hline & Fara & Ali & $\begin{array}{c}\text { Bron } \\
\text { (novice) }\end{array}$ & $\begin{array}{c}\text { Nina } \\
\text { (novice) }\end{array}$ & Rebecca & Anne & $\begin{array}{l}\text { Lynne } \\
\text { (nurse) }\end{array}$ \\
\hline \multicolumn{8}{|l|}{$\begin{array}{l}\text { Interpersonal } \\
\text { strategies }\end{array}$} \\
\hline Greetings & - & + & + & + & + & + & + \\
\hline $\begin{array}{l}\text { Informal terms of } \\
\text { address }\end{array}$ & - & 0 & 0 & + & + & + & - \\
\hline Small talk & - & 0 & - & 0 & + & + & + \\
\hline $\begin{array}{l}\text { Interpersonal } \\
\text { side-sequences }\end{array}$ & 0 & 0 & 0 & 0 & 0 & 0 & 0 \\
\hline Personal disclosure & 0 & 0 & 0 & 0 & 0 & 0 & 0 \\
\hline $\begin{array}{l}\text { Range of empathy/ } \\
\text { reassurance } \\
\text { statements }\end{array}$ & - & - & - & 0 & + & + & 0 \\
\hline $\begin{array}{l}\text { Informal language/ } \\
\text { colloquial terms }\end{array}$ & 0 & 0 & 0 & 0 & + & + & + \\
\hline Tailored explanations & 0 & 0 & 0 & 0 & 0 & 0 & 0 \\
\hline Softening strategies & - & 0 & 0 & + & + & + & + \\
\hline
\end{tabular}

Note. $(-)=$ unsuccessful/limited range or absent; $(0)=$ marginally successful/low range use; $(+)$ $=$ successful/wide range use.

\section{Interpersonal Strategies: Greetings and Forms of Address}

With the exception of Fara (an IMG), all participants introduced themselves to the patient, but only the NESs also provided their role within the hospital.
(1) Bron:
I'm Doctor Pipovicz, [shakes hand] you can call me Bron?
(2) Nina:
My name is Nina, I'm one of the residents with the Emergency Department.

Fara also did not reciprocate the patient's introduction.

(3) Jim (patient): Sorry, I'm Jim.

Fara: Yes uh, nice to meet you.

During the consultation, Fara relied heavily on generic kinship terms and formal terms of address. Similar to the Australian-trained doctors, the other two NNESs, Bron and Ali, made an effort to employ informal forms of address and personal names, although with varying degrees of success.

(4) Fara: I've checked your uh, grandson [...] He is okay, your grandson is okay. 
(5) Ali:

(6) Bron:
Jim. Mr. Jim, how are you?

Yes, er, please let's, er, have a seat and chat about uh, little Aaron?

In the following examples, NESs Anne and Rebecca used first names, and even diminutives (little Aaron) and colloquial metaphors (a real trooper), to indicate their positive feelings toward the boy and thus appear personally concerned and approachable.

(7) Anne:

So Sandra was the nurse who was looking after um little Aaron. [...] he's been a real trooper and uh, as when I was speaking to Sandra, he uh, uh, mm, a wonderful boy.

(8) Rebecca: Are you Aaron's grandfather? Jim? [...] Jim, nice to meet you.

\section{Interpersonal Strategies: Small Talk}

Of the NNESs, only Ali, who had some local experience in a medical practice, although not as a doctor (see Table 1), made any attempt at small talk.

(9) Ali:

Uh is, is your only grandson? Or do you do have any children in the home?

Neither Bron nor Fara made attempt any social talk at all, and Fara failed to pick up on Jim's comment that he needed to talk to his daughter (because she was away-a personal point that affected how Aaron would be cared for and how urgently the family needed news).

(10) Jim (patient): I need to ring my daughter and tell them what's happened.

Fara: And uh, and uh, and uh, just the laceration it uh needs to uh some dressing.

In contrast, all the NESs successfully employed small talk to achieve a number of relational and medical goals (see Coupland, Robinson, \& Coupland, 1994; Maynard \& Hudak, 2008), although Nina, who was less experienced than the others, made only one social statement. Casual small talk help to give medical encounters a more relaxed conversational tone (Ragan, 2000), and comments about Aaron's parents, for example, aided participants in determining the social circumstance of the patient.

(11) Rebecca: $\quad$ Now I understand Aaron's mother is [...] on holidays?

In addition to assisting in providing background to the patient, small talk also allowed the NES doctors to express empathy, build rapport, and reas- 
sure the patient in an indirect way without interrupting the conversational frame of the encounter.

(12) Anne:

(13) Rebecca:

(14) Nina:
Ok. You must have had a pretty hectic morning, I imagine.

Well he's six and I'm sure (he)'d love to see you.

Yeah, exactly and I think he'd like to see his grandfather, a nice friendly face [laughs].

\section{Reassurance and Empathy}

There were key differences in the directness with which NNESs and NESs provided empathic responses and reassuring statements. NNESs relied only on direct reassuring/empathic statements, often repeating the same statement several times. Thus Bron explicitly stated that he wanted to "(re)assure" Jim, and Ali and Fara repeated "There is no problems at all" and "He is okay" four times each, respectively. Despite their good intentions, such tokenistic repetitions might affect the doctor-patient relationship negatively because they can be perceived as insincere (Epstein, 2000) or even raise questions in the patient's or family member's mind as to why they are necessary at all, and might therefore cause additional concern.

(15) Bron:

(16) Ali:

(17) Fara:
I would assume there would, that you're a little bit worried. I'd like to reassure you on some aspects. Yea, actually, first of all I want to tell you no need too much to worry about this condition, he's stable now.

Try not to worry too much.

Most NESs, on the other hand, drew from a much broader range of both direct and indirect statements.

(18) Rebecca: $\quad$ Mm, I'm glad he was wearing a helmet.

[...] I have to reassure you that at the moment he's awake and talking.

Only the more junior doctor, Nina relied mostly on direct statements.

(19) Nina:

I understand that you really worried that's really understandable as well.

So, just to reassure you from the beginning those scans are normal, that everything is fine.

\section{Informal Language Use and Tailored Explanations}

All of the NNESs tried to use informal language, but often with limited success. Difficulties ranged from minor inaccuracies in the use of idioms, such as 
"It's a good news" and "He's on a a good hand now" (Fara), through confusion about lay medical terms "[...] see if the treatment is just a, like a casket [cast] or..." (Bron), to more systemic problems related to the use of medical jargon. Attempts to explain medical terms in providing tailored explanations met with varying degrees of success and sometimes sounded a little odd. NNESs often struggled to find lay alternatives and so returned to their default of medical terminology, sometimes with the addition of hesitations that were open to misinterpretation as professional uncertainty and could therefore lead to a lack of trust (Dahm, 2011a).

(20) Fara: $\quad$ Fortunately, $u h, u h, u h, u h$ I saw the CT scan and the CT scan is normal and there is no (haemorrhage) no any $u h, u h$, uh oedema, nothing and the $u h$, uh head, the head is okay and also we did the abdominal CT and which there is no any abnormality.

During the role-plays, the NESs successfully used a wide range of colloquialisms, idioms, and lay terms.

(21) Nina:

(22) Anne:

(23) Rebecca:
An operation is on the cards.

He got some pain and he's been a real trooper.

Initial stages of sorting out where you know, what what's the damage that it's been done.

By using layperson-friendly terminology, these doctors were able to tailor their explanations to their interlocutor, Jim. However, they tended to use a mixture of medical terminology and informal language. The use of medical terms among trained professionals has been attributed to desensitization and habit, and the locally trained doctors might not have even realized that they were using language that could be difficult for their patients to understand (Bourhis, Roth, \& MacQueen, 1989).

\section{Softening}

NNESs did not show great diversity in their use of the softening strategies (described above and in Caffi, 1999). Bron and Ali softened the impact of their statements through the use of bushes but used normalization only when discussing Aaron's adverse reaction to the contrast.

(24) Ali:

So we only have a fracture bone that we need to obviously hea-, heal it up. It's just a skin rash.

(25) Bron: However some, some patients are: susceptible to uhm:: or prone to reaction $u$, reactions to the contrast. 
They also mitigated their commitment to the truth value of their utterances through the use of quotational shields, but used only two forms of objectivization shields: the passive and exclusive "we" (we = doctors as a professional group).

(26) Ali:

But I have-from the nurse that the, the rashes are very mild [...] I don't think there is anything serious. We especially, there is called some contrast media, there's a dye before doing the CT scan.

(27) Bron: Yes, this is something that we [doctors as professional group] cannot predict, we, we can't know uh.

Fara was most limited in her use of softening strategies and showed hesitations in her use of bushes to soften seriousness. As did Bron and Ali, she employed normalization only to discuss the medical reaction. She was even further limited in her use of objectivization shields and relied solely on the exclusive use of "we" (we = doctors as a professional group).

(28) Fara:

Just the only, mm, thing she had just uh her rash [...] Rash, just rash. Um, just the, the other, uh, sometimes it happens when some (reaction) people take some medicine they can, it can react like that but we [doctors as professional group] can't predict that uh, some people react differently from other peoples.

We [doctors as professional group] gave for the rash also the medicine.

The NESs drew from a wider range of softening strategies including bushes, hedges, and shields.

(29) Anne:

(30) Rebecca:

(31) Lynne:
All these things would be addressed over the next (... ) twenty-four hours.

Or they tell me they have dressed.

And he's had he's had a, I would say, a serious reaction because it had it HAD affected his breathing at one stage.

He was, a little bit upset initially but things have settled and he had a little breathing difficulty?

These Australian doctors were not only able to draw on a larger range of pragmalinguistic resources, but they also used them in a greater variety of contexts. Normalization strategies, for instance, were used to discuss the adverse reaction as well as management. 

gic reaction to that contrast.

(33) Nina: So sometimes what happens when it's broken sometimes they need to fixate the bones.

Objectivization shields (see above) employed by NESs included the deletion of agents, the use of passives, and the use of the plural pronoun "we" to include (we $=$ doctor and patient) or exclude the patient (we = doctors as a professional group).

(34) Nina:

(35) Anne:

So he, subsequently also because he had a bit of a head injury we'd [doctors as professional group] like to do CT scans.

When a CT scan's been done to look for internal bleeding or internal injuries, contrast needs to be given.

(36) Rebecca:

Ah, now we [doctor and patient] might just talk a little bit more about the CT.

All three NNES IMGs, it seems, struggled to create a more informal atmosphere, employed tokenistic and repetitive empathic or reassuring statements, and drew from a limited range of softening strategies. They therefore ran the risk of appearing less approachable, with consequent effects on rapport within a patient-centred approach.

Although it is beyond the scope of this article to speculate too far on what may have influenced the NNESs to use fewer of the approachability features under discussion here, it does seem that competence in colloquial English and (local) medical experience were important in the extent to which they used these approachability features. It is difficult to establish with any clarity how far the performance of the NNESs in a study of this kind was influenced by sociopragmatic and pragmalinguistic issues. Indeed, the two are not always so easily separated. Did the NNESs use fewer approachability features than their NES counterparts for sociopragmatic or pragmalinguistic reasons? The former would suggest that they were unsure how "approachable" they were expected to be in this role (as may be the case with Bron, who was married to an Australian and more competent in social English, but who lacked practical professional experience in Australia). The latter would indicate that they were unsure about the pragmalinguistic features, that is, the actual linguistic expressions they could use in order to appear more approachable.

Whatever the root cause, however, these results suggest that they would benefit from greater exposure to and insight into the conduct of medical consultations in an Australian environment. Ideally, mentoring and internship programs would help in this process of socialization into the locally relevant sociopragmatic expectations and pragmalinguistic resources associated with patient-centred medicine. However, such opportunities are limited. More- 
over, such interpersonal aspects of intercultural pragmatics are notoriously difficult to acquire without explicit instruction. In the following section we suggest some of the implications of our study for the design and delivery of communications training courses specifically targeted at IMGs.

\section{Implications for Teaching}

As noted above, sociopragmatic understandings and pragmalinguistic competence are very closely linked. This means that learners are unlikely to use a particular pragmalinguistic feature if they do not know why it is needed or are not convinced of its necessity. The nature of pragmatic transfer from a first or early-learned language is such that pragmatic features and the sociopragmatic values that motivate their use simply appear to be "right" and "natural," rather than cross-culturally variable (Yates, 2004, 2008). IMGs may not use the kinds of approachability features discussed above to the extent that their counterparts trained in Canada or Australia do-even if they are already part of their repertoire-if they do not realize that this is expected of them in their role as doctors. If they have been trained in a very different approach to medicine or communicative culture, they may focus on the disease rather than on the whole person, and they may even regard the personal asides and fictional egalitarianism expected in patient-centred approaches as not only unnecessary, but also insincere and perhaps even patronizing. This makes it vital that instruction in pragmalinguistic features of interaction also include sociopragmatic exploration of the general and medical communicative ethos of both the culture in which they intend to practice and of the one in which they were trained.

The pragmalinguistic devices signalling approachability that were used more often by the NES participants were

- appropriate greetings/introductions, forms of address

- informal language

- appropriate lay (medical) terminology to tailor explanations to interlocutor

- range of reassuring/social/empathic statements

- softening strategies.

As noted above, although instructors could deal with these in the classroom as discrete items - and at various points in the teaching and learning process it may be helpful to do so-the devices also need to be closely related to the context in which they are used and to the contextual sociopragmatic values that are driving their use. Authentic or quasi-authentic texts are useful in providing models in context, and these can provide illuminating samples. Learners can be guided to scrutinize these for relevant recurring features, and then to reflect on how and why they are used (see Newton, 2004; O'Grady, 2011). For example, a guided examination of a brief extract such as the follow- 
ing, taken from the examination phase of a naturally occurring consultation between a colorectal surgeon and a patient, can help learners attend to and reflect on the use of particular approachability features (for more information on this study see $\mathrm{O}^{\prime}$ Grady et al., in press):

[...] So come on up here on the bunk. Thanks. So now I want you to leave everything on, shoes, everything, and just lie up on the bunk like go on your back looking up at the roof. Swing your legs up. That's the way. Let's loosen your belt. That's good. Yes, I need you to lift up your tail for me. There we go. I'm just going to cover your middle over here with a, a sheet. Just have a little feel of your tummy. [Unclear].

Stay there. Don't, don't move [unclear]. [...] There you go. I'll get you to wriggle back onto your back 'cause you're really close to the edge. I don't want you to fall off. Good.

[....] That's nice. I'll get you to wriggle over on your side for me facing that way. I interrupted you there. What were you going to say?

A cyclical approach to exploiting the model can guide the learners to identify the context, and lead them to an identification of the features found there and then back to the context to consider why they were used (see Yates, 2004, 2008; also Newton, 2004; O'Grady, 2011). Learners could be set various tasks to guide them toward relevant features and to reflect on why they are used. For example:

- Who is the speaker? What is he/she doing? Explain your reasoning.

- Reflect on this doctor's style. What did you notice about it?

- Would you speak in a similar way? How would you give similar instructions in your country of origin?

- Are there any differences? Why might they be different?

- Look at the words in bold. What do they mean and why were these particular words chosen?

- In what different ways does the doctor give the patient instructions? Would you do it this way? Why/why not?

- What explanations does the doctor give?

- Why do you think the doctor says the following phrases?

- That's nice.

- What were you going to say?

- That's the way.

- There we go.

- There you go.

While it is important in pragmatics instruction to avoid presenting either culture or cultural norms as monolithic or unchanging, it is useful to allow 
time and space for reflection on how features of interaction might vary across situations, contexts, and cultures. Our role as teachers is to help learners understand this variation and what it looks like, so that newcomers to a culture are in a position to understand more about how they would or would not use similar features in the other languages they speak, and reflect on how they want to communicate in the new context for which they are preparing. As many have noted, how far learners put into practice what they have learned of the sociopragmatics and pragmalinguistics of their new environment should ultimately be a matter of personal choice: our responsibility as teachers is to provide them with the tools they will need to identify and understand what happens and why. We can also provide space for reflection and experimentation so they can try out various devices in the relative safety of the classroom before they branch out to apply them in actual practice.

\section{Conclusion}

Although this pilot study has focused on one particular aspect of one particular genre that is part of the repertoire of communication skills required by one particular profession in one cultural context, it makes an important contribution to our understanding of the microlevel of how speakers actually reflect and perpetuate macrolevel values through talk. Because the norms for interpersonal communication in any genre are embedded in the communicative ethos of the wider community, what works on an interpersonal level in the consultation room is very closely related to what will also work elsewhere.

Moreover, the kind of interpersonal rapport that these approachability features help to generate is by no means a trivial part of interaction in any workplace or, indeed, outside it. Social interaction at work plays a major role in accomplishing job tasks, not only in Australia but also in other workplaces around the world (see, for example, Derwing \& Waugh, 2012; Holmes, 2000). The understandings highlighted in this study therefore make an important contribution to the development of an evidence base from which we can create instructional materials capable of providing transnationals - not only doctors - with a concrete appreciation of how interaction works in a new culture and the tools to discover for themselves how these and other elements work. Both the features on which we have focused and the methodology that we have used, therefore, have a much wider application to the provision of relevant general language instruction, as well as workplace preparation for a range of newcomers, whatever their goals.

\footnotetext{
Notes

${ }^{1}$ Defined as having had their schooling and training in Australia. In fact, like much of the urban population, two were multilingual, having arrived in Australia in their infancy.
} 


\section{Acknowledgements}

The authors wish to thank the participants and actors, and the staff at the simulation training facilities. The authors would also like to thank two anonymous reviewers for their valuable comments on an earlier draft of this article, and Sophia Khan for editing assistance. This project was funded by the Partnership Seeding Scheme at Macquarie University, Sydney, Australia.

\section{The Authors}

Maria R. Dahm is an Early Career Fellow in the Department of Linguistics at Macquarie University. She completed her $\mathrm{PhD}$ on the impact of medical terminology on English-medium consultations. Maria's research interests include communication and culture in intercultural workplace contexts, experiences and challenges for international medical graduates, and English for Specific Purposes.

Lynda Yates is currently Associate Professor and Head of Linguistics at Macquarie University, Sydney. Her professional experience teaching adult TESOL and consulting to industry have fuelled an interest in research that can feed into the practical concerns of adult language learners and their teachers, and in particular the pronunciation and pragmatic needs of immigrants and transnational professionals. She has a strong commitment to the translation of research findings into professional practice.

\section{References}

Adolphs, S., Atkins, S., \& Harvey, K. (2007). Caught between professional requirements and interpersonal needs: Vague language in healthcare contexts. In J. Cutting (Ed.), Vague language explored (pp. 62-78). New York, NY: Palgrave Macmillan.

Australian Institute of Health and Welfare. (2011). Medical labour force 2009 detailed tables. Table 9: Employed medical practitioners, by country of first qualification(a), states and territories, 2009. Canberra: Author. Retrieved from http://www.aihw.gov.au/workforce-data/

Australian Medical Council. (2009). Australian Medical Council annual report 2008. Retrieved from http://www.amc.org.au/images/publications/2008-AMC-Annual-Report.pdf

Australian Medical Council. (2011). Australian Medical Council annual report 2009. Retrieved from http://www.amc.org.au/images/publications/2009-annual-report.pdf

Australian Medical Council, (2012a). Australian Medical Council annual report 2010. Retrieved from http://www.amc.org.au/images/publications/Australian-Medical-Council-AnnualReport-2010.pdf

Australian Medical Council. (2012b). Australian Medical Council annual report 2011. Retrieved from http://www.amc.org.au/images/publications/Australian-Medical-Council-AnnualReport-2011.pdf

Bataller, R., \& Shively, R. (2011). Role plays and naturalistic data in pragmatics research: Service encounters during study abroad. Journal of Linguistics and Language Teaching (JLLT), 2(1), $15-50$.

Bates, J., \& Andrew, R. (2001). Untangling the roots of some IMGs' poor academic performance. Academic Medicine, 76(1), 43-46.

Birrell, B., \& Schwartz, A. (2006). Accreditation of overseas trained doctors: The continuing crisis. People and Place, 14(3), 37-47.

Bourhis, R. Y., Roth, S., \& MacQueen, G. (1989). Communication in the hospital setting: A survey of medical and everyday language use amongst patients, nurses and doctors. Social Science and Medicine, 28(4), 339-346.

Caffi, C. (1999). On mitigation. Journal of Pragmatics, 31(7), 881-909.

Canadian Medical Association. (2013). Physicians by country of MD graduation, Canada, 19962013. Retrieved from http://www.cma.ca/multimedia/CMA/Content_Images/Inside_cma/ Statistics/10PhysByCountry.pdf 
Centre for Canadian Language Benchmarks. (2009). Language for work: CLB and essential skills for ESL instructors. Retrieved from http://www.language.ca/documents/esi_for_instructors.pdf

Centre for Canadian Language Benchmarks. (2012). CLB support kit. Retrieved from http://www. language.ca/documents/clb_support_kit_1.pdf

Clyne, M. (2006). Some thoughts on pragmatics, sociolinguistic variation, and intercultural communication. Intercultural Pragmatics, 3(1), 95-105.

Cordella, M., \& Musgrave, S. (2009). Oral communication skills of international medical graduates: Assessing empathy in discourse. Communication \& Medicine, 6(2), 129-142.

Coupland, J., Robinson, J. D., \& Coupland, N. (1994). Frame negotiation in doctor-elderly patient consultations. Discourse \& Society, 5(1), 89-124.

Dahm, M. R. (2011a). Exploring perception and use of everyday language and medical terminology among international medical graduates in a medical ESP course in Australia. English for Specific Purposes, 30(3), 186-197.

Dahm, M. R. (2011b). Patient centred care: Are international medical graduates "expert novices"? Australian Family Physician, 40(11), 895-900.

Derksen, F., Bensing, J., \& Lagro-Janssen, A. (2013). Effectiveness of empathy in general practice: A systematic review. British Journal of General Practice, 63(606), 76-84.

Derwing, T. M., \& Waugh, E. (2012). Language skills and the social integration of Canada's adult immigrants (IRPP Study 31). Montreal, QC: Institute for Research on Public Policy.

Epstein, R. M. (2000). The science of patient-centered care. Journal of Family Practice, 49(9), 805807.

Gassner, D. (2012). The thing about thing: Use of vague language in L1 and L2 speaker employment interviews in Australia (Unpublished doctoral dissertation). Macquarie University, Australia.

Goddard, C. (2006). "Life your game, Martina!": Deadpan jocular irony and the ethnopragmatics of "Aussie" English. In C. Goddard (Ed.), Ethnopragmatics: Understanding discourse in cultural context (pp. 65-97). Berlin, Germany: Mouton de Gruyter.

Goddard, C. W. (2009). Not taking yourself too seriously in Australian English: Semantic explications, cultural scripts, corpus evidence. Intercultural Pragmatics, 6(1), $29-53$.

Hadlow, J., \& Pitts, M. (1991). The understanding of common health terms by doctors, nurses and patients. Social Science and Medicine, 32(2), 193-196.

Hall, J. A., Roter, D. L., \& Katz, N. R. (1988). Meta-analysis of correlates of provider behavior in medical encounters. Medical Care, 26(7), 657-675.

Hall, P., Keely, E., Dojeiji, S., Byszewski, A., \& Marks, M. (2004). Communication skills, cultural challenges and individual support: Challenges of international medical graduates in a Canadian healthcare environment. Medical Teacher, 26(2), 120-125.

Harvey, K., \& Adolphs, S. (2012). Discourse and healthcare. In J. P. Gee \& M. Handford (Eds.), The Routledge handbook of discourse analysis (pp. 470-481). New York, NY: Routledge.

Holmes, J. (2000). Talking English from 9 to 5: Challenges for ESL learners at work. International Journal of Applied Linguistics, 10(1) 125-140.

Holmes, J., \& Riddiford, N. (2011). From classroom to workplace: Tracking socio-pragmatic development. ELT Journal, 65(4), 376-386.

Horne, D. (1964). The lucky country: Australia in the sixties. Ringwood, Australia: Penguin.

Hudak, P. L., \& Maynard, D. W. (2011). An interactional approach to conceptualising small talk in medical interactions. Sociology of Health and Illness, 33(4), 634-653.

Kachru, B. B. (1992). The other tongue: English across cultures. Urbana, IL: University of Illinois Press.

Kasper, G. (2000). Data collection in pragmatics research. In H. Spencer-Oatey (Ed.), Culturally speaking: Managing rapport through talk across cultures (pp. 316-341). London, UK: Continuum.

Khalil, T., \& Bhopal, J. S. (2009). The patient-centred interview and international medical graduates: A preliminary view. British Columbia Medical Journal, 51(6), 246-249.

Laroche, L., \& Rutherford, D. (2007). Recruiting, retaining, and promoting culturally different employees. Burlington, MA: Elsevier. 
Levinson, W., Gorawara-Bhat, R., \& Lamb, J. (2000). A study of patient clues and physician responses in primary care and surgical settings. Journal of the American Medical Association, 284(8), 1021-1027.

Lockyer, J., Fidler, H., de Gara, C., \& Keefe, J. (2010). Learning to practice in Canada: The hidden curriculum of international medical graduates. Journal of Continuing Education in the Health Professions, 30(1), 37-43.

Marra, M., Vine, B., \& Holmes, J. (2008, July). Heroes, fathers and good mates: Leadership styles of men at work. In E. Tilley (Ed.), Power and place: Refereed proceedings of the Australian and New Zealand Communication Association Conference, Wellington, NZ, 1-15. Retrieved from http://www.anzca.net/conferences/past-conferences/47-adam.html

Martin, D. (2003). Martin's map: A conceptual framework for teaching and learning the medical interview using patient-centred approach. Medical Education, 37(12), 1145-1153.

Maynard, D. W., \& Hudak, P. L. (2008). Small talk, high stakes: Interactional disattentiveness in the context of prosocial doctor-patient interaction. Language in Society, 37(5), 661-688.

McDonnell, L., \& Usherwood, T. (2008). International medical graduates: Challenges faced in the Australian training program. Australian Family Physician, 37(6), 481-484.

McGrath, P., Henderson, S., Holewa, H. A., Henderson, D., \& Tamargo, J. (2012). International medical graduates' reflections on facilitators and barriers to undertaking the Australian Medical Council examination. Australian Health Review, 36(3), 296-300.

Moore, R., Yelland, M., \& Ng, S. K. (2011). Moving with the times: Familiarity versus formality in Australian general practice. Australian Family Physician, 40(12), 1004-1007.

Mullan, F. (2005). The metrics of the physician brain drain. New England Journal of Medicine, 353(17), 1810-1818.

Newton, J. (2004). Face-threatening talk on the factory floor: Using authentic workplace interactions in language teaching. Prospect, 19(1), 47-64.

Norfolk, T., Birdi, K., \& Walsh, D. (2007). The role of empathy in establishing rapport in the consultation: A new model. Medical Education, 41(7), 690-697.

O'Grady, C. (2011). Teaching the communication of empathy in patient-centred medicine. In B. J. Hoekje \& S. M. Tipton (Eds.), English language and the medical profession: Instructing and assessing the communication skills of international physicians (pp. 43-72). Bingley, UK: Emerald.

O'Grady, C., Dahm, M. R., Roger, P., \& Yates, L. (in press). Trust, talk and the dictaphone: Tracing the discursive accomplishment of trust in a surgical consultation. Discourse $\&$ Society.

Peeters, B. (2004). "Thou shalt not be a tall poppy": Describing an Australian communicative (and behavioral) norm. Intercultural Pragmatics, 1(1), 71-92.

Pilotto, L. S., Duncan, G. F., \& Anderson-Wurf, J. (2007). Issues for clinicians training international medical graduates: A systematic review. Medical Journal of Australia, 187(4), 225-228.

Prince, E., Frader, J., \& Bosk, C. (1982). On hedging in physician-physician discourse. In R. J. Di Pietro (Ed.), Linguistics and the professions: Proceedings of the second annual Delaware symposium on language studies (pp. 83-97). Norwood, NJ: Ablex.

Ragan, S. (2000). Sociable talk in women's health care contexts: Two forms of non-medical talk. In J. Coupland (Ed.), Small talk (pp. 269-287). Harlow, UK: Pearson Education.

Sommer, J., MacDonald, W., Bulsara, C., \& Lim, D. (2012). Grunt language versus accent: The perceived communication barriers between international medical graduates and patients in Central Wheatbelt catchments. Australian Journal of Primary Health, 18(3), 197-203.

Spencer-Oatey, H., Işik-Güler, H., \& Stadler, S. (2012). Intercultural communication. In J. P. Gee \& M. Handford (Eds.), The Routledge handbook of discourse analysis (pp. 572-586). New York, NY: Routledge.

Stewart, M., Brown, J. B., Weston, W. W., McWhinney, I. R., McWilliam, C. L., \& Freeman, T. R. (2003). Patient-centered medicine: Transforming the clinical method (2nd ed.). Oxon, UK: Radcliffe.

Street, R. L. (1991). Information-giving in medical consultations: The influence of patients' communicative styles and personal characteristics. Social Science \& Medicine, 32(5), 541-548. 
Street, R. L. (2003). Communication in medical encounters: An ecological perspective. In T. L. Thompson, A. M. Dorsey, K. I. Miller, \& R. Parrott (Eds.), Handbook of health communication (pp. 63-89). Mahwah, NJ: Lawrence Erlbaum.

Tannen, D., \& Wallat, C. (1987). Interactive frames and knowledge schemas in interaction: Examples from a medical examination/interview. Social Psychology Quarterly, 50(2), 205-216.

Thomas, J. (1983). Cross-cultural pragmatic failure. Applied Linguistics, 4(2), 91-112.

Tipton, S. (2005). Improving international medical graduates' performance of case presentations. Journal of Applied Linguistics and Professional Practice, 2(3), 395-406.

Wierzbicka, A. (1994). "Cultural scripts": A semantic approach to cultural analysis and crosscultural communication. Pragmatics and Language Learning, 5, 1-24.

Yates, L. (2000). "Ciao, guys!": Mitigation addressing positive and negative face concerns in the directives of native-speaker and Chinese background speakers of Australian English (Unpublished doctoral dissertation). La Trobe University, Australia.

Yates, L. (2004). The "secret rules of language": Tackling pragmatics in the classroom. Prospect, 19(1), 3-21.

Yates, L. (2005). Negotiating an institutional identity: Individual differences in NS and NNS teacher directives. In K. Bardovi-Harlig \& B. Hartford (Eds.), Interlanguage pragmatics: Exploring institutional talk (pp. 67-99). Mahwah, NJ: Lawrence Erlbaum.

Yates, L. (2008). The not-so generic skills: Teaching employability communication skills to adult migrants. Sydney, Australia: National Centre for English Language Teaching and Research.

Yates, L. (2010). Speech act performance in workplace settings. In A. Martinez-Flor \& E. Usó-Juan (Eds.), Speech act performance: Theoretical, empirical and methodological issues (pp. 109-126). Amsterdam, Netherlands: John Benjamins.

Yates, L., Dahm, M., Roger, P., \& Cartmill, J. (2013). Rapport and teamwork in Australia: Insights for international medical graduates. Manuscript submitted for publication.

Zulla, R., Baerlocher, M. O., \& Verma, S. (2008). International medical graduates (IMGs) needs assessment study: Comparison between current IMG trainees and program directors. BMC Medical Education, 8, 42-47. 